\title{
Prediction of Partition Coefficients in SDS Micelles by DFT Calculations
}

\author{
Leila Saranjam $^{1}$, Elisabet Fuguet ${ }^{2}$, Miroslava Nedyalkova ${ }^{3} \mathbb{D}$, Vasil Simeonov ${ }^{3}$ D, Francesc Mas $^{1}$ (D) \\ and Sergio Madurga $1, *$ (D)
}

1 Department of Material Science and Physical Chemistry, Research Institute of Theoretical and Computational Chemistry (IQTCUB), University of Barcelona, C/Martí i Franquès 1, 08028 Barcelona, Spain; Lsaransa19@alumnes.ub.edu (L.S.); fmas@ub.edu (F.M.)

2 Department of Chemical Engineering and Analytical Chemistry, Institute of Biomedicine (IBUB), University of Barcelona, C/Martí i Franquès 1, 08028 Barcelona, Spain; elifuguetj@ub.edu

3 Faculty of Chemistry and Pharmacy, University of Sofia "St. Kl. Ohridski", 1 James Bourchier Blvd., 1164 Sofia, Bulgaria; nhmn@chem.uni-sofia.bg (M.N.); vsimeonov@chem.uni-sofia.bg (V.S.)

* Correspondence: s.madurga@ub.edu

Citation: Saranjam, L.; Fuguet, E.; Nedyalkova, M.; Simeonov, V.; Mas, F.; Madurga, S. Prediction of Partition Coefficients in SDS Micelles by DFT Calculations. Symmetry 2021, 13, 1750. https://doi.org/10.3390/sym 13091750

Academic Editor: Enrico Bodo

Received: 28 July 2021

Accepted: 13 September 2021

Published: 19 September 2021

Publisher's Note: MDPI stays neutral with regard to jurisdictional claims in published maps and institutional affiliations.

Copyright: (C) 2021 by the authors. Licensee MDPI, Basel, Switzerland. This article is an open access article distributed under the terms and conditions of the Creative Commons Attribution (CC BY) license (https:// creativecommons.org/licenses/by/ $4.0 /)$.

\begin{abstract}
A computational methodology using Density-Functional Theory (DFT) calculations was developed to determine the partition coefficient of a compound in a solution of Sodium Dodecyl Sulfate (SDS) micelles. Different sets of DFT calculations were used to predict the free energy of a set of 63 molecules in 15 different solvents with the purpose of identifying the solvents with similar physicochemical characteristics to the studied micelles. Experimental partition coefficients were obtained from Micellar Electrokinetic Chromatography (MEKC) measurements. The experimental partition coefficient of these molecules was compared with the predicted partition coefficient in heptane/water, cyclohexane/water, $N$-dodecane/water, pyridine/water, acetic acid/water, decan-1$\mathrm{ol}$ /water, octanol/water, propan-2-ol/water, acetone/water, propan-1-ol/water, methanol/water, 1,2-ethane diol/water, dimethyl sulfoxide/water, formic acid/water, and diethyl sulphide/water systems. It is observed that the combination of pronan-1-ol/water solvent was the most appropriated to estimate the partition coefficient for SDS micelles. This approach allowed us to estimate the partition coefficient orders of magnitude faster than the classical molecular dynamics simulations. The DFT calculations were carried out with the well-known exchange correlation functional B3LYP and with the global hybrid functional M06-2X from the Minnesota functionals with 6-31++G ** basis set. The effect of solvation was considered by the continuum model based on density (SMD). The proposed workflow for the prediction rate of the participation coefficient unveiled the symmetric balance between the experimental data and the computational methods.
\end{abstract}

Keywords: partition coefficient; computational prediction; micelle; SDS; DFT; $\log \mathrm{P}$

\section{Introduction}

A compound's solvent-water partition coefficient $(\log \mathrm{P})$ measures the equilibrium ratio of the compound's concentrations in a two-phase system, as for example, two immiscible solvents or a system of micelles in an aqueous solution [1]. It must be noted that $\log \mathrm{P}$ is used to determine the partition among different phases for nonionic molecules. However, in the case of molecules having acid/base functional groups, the distribution coefficient, $\log \mathrm{D}$, should be used [2]. It is known that the partition coefficient is related to the physicochemical properties of the molecules, being a measure of their hydrophilic (water-loving)/hydrophobic (water-fearing) character [3].

Micelles are important systems applied in drug delivery methods. One determining factor in this kind of application is the partition coefficient of the potential drug. Thus, the LogP parameter indicates the capacity of a potential drug to aggregate with the micelles as it is related to the thermodynamic equilibrium of the distribution of the compound 
between the water and the system of micelles. In aqueous solutions, micelles consist of a hydrophobic core and a hydrophilic external layer, which is created by the surfactant head groups, directly in contact with the surrounding aqueous phase. Thus, because of the existing polarity gradient, aqueous-micellar solutions can solubilize polar and nonpolar materials [4].

The partition coefficient of molecules in a system of micelles can be experimentally obtained by chromatographic techniques such as micellar electrokinetic chromatography (MEKC) [5-7]. From a computational point of view, the prediction of $\log P$ in systems of micelles could be performed by using molecular structures of micelles obtained by dynamic simulations (MDs) [8]. MD simulations starting from pre-assembled SDS (sodium dodecyl sulphate), CTAB (cetyltrimethylammonium bromide), C12E10, Brij35 (C12E23), Triton X-114 and Triton X-100 micelles were used to obtain micelles structures to be used as input for COSMOmic to predict micelle water partition coefficients [9]. Good accuracy was obtained in the prediction of $\log \mathrm{P}$ for neutral and charged solutes in micellar systems using MD simulations in combination with umbrella sampling techniques [10]. Recently, the partition coefficients were determined for the mixed system of sodium laureth sulphate (SLES) and fatty acids [11]. In this work, good agreement with the experimental data for the neutral solutes of capric acid and palmitic acid were obtained using both MD and COSMOmic approaches. However, for simulating charged solutes in anionic surfactant micelles, the use of an accurate polarizable force field was crucial to predict logP for the anion forms.

Here, we present a computational methodology to predict logP for systems of micelles using DFT calculations based in the prediction of partition coefficients in pure solvents that could be less time consuming and of general application [12,13]. It must be noted that there are several approaches to determine the partition coefficient between pure phases [14-21]. Some approaches use quantum calculations and others a fragment approach. In general, these methodologies are based on the calculation of the partition coefficients of molecules through the estimation of the transfer free energy between the two phases. In the fragment approach, the logarithm of the partition coefficient of a solute $(\log \mathrm{P})$ is determined by the sum of the values corresponding to each constitutive molecular fragment, the socalled fragment constant. However, methodologies based on fragment approaches are parameterized for a limited number of solvents (generally octanol/water) and they are not suitable for predicting properties in other solvents.

In the proposed methodology, the partition of molecules between the aqueous phase and the micelles could be related to the partition coefficient between aqueous phase and a hypothetical solvent with similar physicochemical characteristics to the system of micelles. In the present work, the prediction of solvent/water partition coefficients in a set of 15 organic solvents was carried out by applying density functional theory (DFT) calculations. Here, this methodology is used to determine the partition coefficient of a compound in a solution of Sodium Dodecyl Sulphate (SDS) micelles. The Solvation Model Based on Density (SMD) is an appropriated model for the estimation of solvation free energies [22,23]. This methodology is applied with Becke three-parameter Lee-Yang-Parr B3LYP [24-26] and M06-2X [27] functionals. Finally, a comparison with experimental octanol/water partition coefficients is also performed to estimate the accuracy of the methodology.

\section{Materials and Methods}

\subsection{Apparatus and Conditions}

MEKC determinations were performed in a in a Beckman (Palo Alto, CA, USA) P/ACE System 5500 capillary electrophoresis equipped with a UV diode array detector. A fused silica capillary with a total length of $47 \mathrm{~cm}$ (40 cm of effective length) and $50 \mu \mathrm{m}$ of internal diameter was used. Measurements were made at $25{ }^{\circ} \mathrm{C}$ and $+15 \mathrm{kV}$. Detection was set at $214 \mathrm{~nm}$. The test compounds were injected into the capillary by pressure, applying 0.5 p.s.i. during $1 \mathrm{~s}$. 
The capillary was conditioned with the following sequence: $5 \mathrm{~min}$ of water, $20 \mathrm{~min}$ of $1 \mathrm{M}$ sodium hydroxide solution, $10 \mathrm{~min}$ of water, $10 \mathrm{~min}$ of $0.1 \mathrm{M}$ sodium hydroxide solution and 20 min of separation buffer. Prior to each injection the capillary was flushed with 5 min of separation buffer.

The $40 \mathrm{mM}$ SDS separation buffer was prepared by solving the corresponding amount of surfactant in a $20 \mathrm{mM}$ sodium phosphate buffer at $\mathrm{pH}$ 7.0. Test compounds were solved in a methanol solution (used as electroosmotic flow marker), which already contained $2 \mathrm{mg} \mathrm{ml}^{-1}$ of phenyl-undecylketone (used as micellar marker). Concentration of the test compounds was $2 \mathrm{mg} \mathrm{mL}^{-1}$. All solutions were filtered through $0.45 \mu \mathrm{m}$ nylon syringe filters (Albet). All measurements were taken by triplicate.

\subsection{Determination of Partition Coefficients in SDS Micelles}

In MEKC, neutral molecules are separated according to their distribution between the aqueous phase and the micellar phase. The retention factor, $k$, of a compound can be calculated according to the following equation:

$$
k=\frac{t_{R}-t_{0}}{t_{0}\left(1-t_{R} / t_{m}\right)}
$$

where $t_{R}$ is the retention time of the compound of interest, and $t_{0}$ and $t_{m}$ the retention times of the electroosmotic flow and micellar markers (methanol and phenyl-undecylketone, respectively).

In this study, previously measured retention times [5,6] were used to obtain the partition coefficients between water and SDS micelles using the following relation

$$
k=P \frac{v\left(C_{T}-C M C\right)}{1-v\left(C_{T}-C M C\right)}
$$

where $P$ is the partition coefficient of a compound distributed between the micellar and the aqueous phase, $v$ is the partial molar volume of the surfactant [7], $C_{T}$ is the total concentration of surfactant, $C M C$ is the critical micellar concentration and $k$ is the MEKC retention factor of the test compound. CMC is obtained from conductimetric analysis [28]. Thus, all partition coefficients (Table 1 ) were determined under the same conditions: $40 \mathrm{mM}$ SDS micelles solution, in $20 \mathrm{mM}$ phosphate buffer at $\mathrm{pH} 7$ at $25^{\circ} \mathrm{C}$.

Table 1. List of experimental partition coefficients of compounds in SDS micelles (Log $\mathrm{P}_{\mathrm{SDS}}$ ) determined from retention factors obtained from MECK experiments with $40 \mathrm{mM}$ SDS micelles solution, in $20 \mathrm{mM}$ phosphate buffer at $\mathrm{pH} 7$ at $25^{\circ} \mathrm{C}$ using Equation (2).

\begin{tabular}{cc}
\hline Compound & Log PSS \\
\hline Ethylbenzene & 2.71 \\
Propylbenzene & 3.20 \\
Butylbenzene & 3.70 \\
1-phenylethanone & 2.08 \\
1-phenylpropan-1-one & 2.41 \\
1-phenylbutan-1-one & 2.77 \\
1-phenylpentan-1-one & 3.18 \\
1-phenylheptan-1-one & 4.17 \\
Furan & 1.26 \\
2-nitroaniline & 2.16 \\
2,3-benzofuran & 2.44 \\
Diphenylmethanone & 3.25 \\
Benzamide & 1.60 \\
4-chloroaniline & 2.18 \\
2,3-dimethylphenol & 2.31 \\
Naphthalen-2-ol & 2.73 \\
\hline
\end{tabular}


Table 1. Cont.

\begin{tabular}{|c|c|}
\hline Compound & $\log P_{\text {SDS }}$ \\
\hline 4-aminobenzamide & 1.27 \\
\hline 3-methylphenol & 1.97 \\
\hline 2,4-dimethylphenol & 2.38 \\
\hline Naphthalene & 3.04 \\
\hline Pyrimidine & 0.78 \\
\hline Benzaldehyde & 1.90 \\
\hline 3-chloroaniline & 2.15 \\
\hline Pyrrole & 1.04 \\
\hline 3-nitroaniline & 1.91 \\
\hline 4-chlorophenol & 2.25 \\
\hline Phenol & 1.58 \\
\hline Methylbenzoate & 2.40 \\
\hline Bromobenzene & 2.60 \\
\hline 1,4-xylene & 2.77 \\
\hline Benzene-1,3-diol & 1.27 \\
\hline 2-methylaniline & 1.90 \\
\hline 1-methoxy-2-nitrobenzene & 2.17 \\
\hline $\mathrm{N}$-4-chlorophenylacetamide & 2.43 \\
\hline Aniline & 1.59 \\
\hline Nitrobenzene & 1.99 \\
\hline Chlorobenzene & 2.44 \\
\hline$N$-phenylacetamide & 1.78 \\
\hline 4-nitroaniline & 1.94 \\
\hline Anisole & 2.10 \\
\hline Benzonitrile & 1.91 \\
\hline 1-ethyl-4-nitrobenzene & 2.83 \\
\hline 1-methoxy-4-nitrobenzene & 2.36 \\
\hline$N, N$-diethyl-4-nitroaniline & 3.42 \\
\hline Benzyl benzoate & 3.96 \\
\hline Caffeine & 1.67 \\
\hline Corticosterone & 3.99 \\
\hline Cortisone & 3.39 \\
\hline$\beta$-Estradiol & 4.08 \\
\hline Estriol & 3.12 \\
\hline Cortisol & 3.44 \\
\hline Hydroquinone & 1.03 \\
\hline Quinoline & 2.59 \\
\hline Atrazine & 2.84 \\
\hline Diuron & 2.92 \\
\hline Fluometuron & 2.56 \\
\hline Isoproturon & 2.83 \\
\hline Linuron & 3.08 \\
\hline Metobromuron & 2.66 \\
\hline Monuron & 2.34 \\
\hline Metoxuron & 2.44 \\
\hline Phenyl urea & 1.78 \\
\hline Propazine & 3.13 \\
\hline
\end{tabular}

\subsection{Computational Determination of Partition Coefficients}

The use of quantum chemistry is a powerful and valuable alternative method for calculating partition coefficients of a sparse set of compounds. Here, it is applied to study the partition behaviour of 63 molecules. For all compounds, a single conformation is used. For flexible molecules, the most extended conformation is selected.

All compounds were geometrically optimized using Density Functional Theory (DFT) with B3LYP and M06-2X [27] methods with 6-31++G ** basis set and using the continuum solvation model based on density (SMD) [22,29]. SMD can be applied to any charged or uncharged solute in any type of solvent as a universal solvation model. This model 
divides the solvation free energy into two main parts: the bulk electrostatic part and the cavity dispersion part. The main benefit of this methodology using DFT is that, in principle, this method is universal, and it can be applied for any molecule. Calculations were performed with the electronic structure program Gaussian 16 [30] that provides a wide-ranging suite for prediction of molecular properties. The initial structures of the molecules were generated by the free cross-platform molecule editor Avogadro [31]. Only solvation energies obtained from minimizations with all positive frequencies were considered. Harmonic vibrational frequencies were calculated for all compounds. The thermochemical values are calculated at $298.15 \mathrm{~K}$ and $1.0 \mathrm{~atm}$.

The partition coefficient of a molecule is related to the Gibbs free energy of transfer, $\Delta G^{\circ}$ solv/wat, between water and a particular solvent. This free energy is therefore obtained via calculation of absolute solvation free energies in the respective media by [12]

$$
\begin{aligned}
\Delta G^{\circ} \text { solv } / \text { wat } & =\Delta G^{\circ} \text { solvent }-\Delta G^{\circ} \text { water } \\
\log P & =\frac{-\Delta G^{\circ} \text { solv } / \text { wat }}{R T \ln 10}
\end{aligned}
$$

where $R$ is the molar gas constant and $T$ is the temperature (298.15 K). It should be noted that a symmetric distribution of solvation energies of right-hand terms of Equation (3) will correspond to a null Gibbs free energy of transfer, meaning a similar distribution of the molecule between both solvents.

\subsection{Statistical Analysis}

Linear regression analysis was performed with the regression data analysis tool of Microsoft Excel (version 2108) to obtain coefficients, confidence intervals and standard errors, F statistics, significant $\mathrm{F}$ and $p$-values and Pearson correlation coefficient $\left(\mathrm{R}^{2}\right)$.

To evaluate the prediction of experimental octanol/water logP values, several statistical measures were also calculated: mean absolute error (MAE), mean square error (MSE), and root mean square error (RMSE). Equations of these measures are indicated in the Supplementary Materials.

\section{Results and Discussion}

\subsection{Identification of Best Solvents for Prediction of Log P in SDS Micelles}

In this work, the partition coefficients with respect to water of 63 compounds (Table 1) were predicted in 15 different solvents. The structures of the solvents used are shown in Figure S1 in the Supplementary Materials. The experimental partition coefficients in SDS micelle of those molecules were correlated with respect to the predicted partition coefficients in all 15 solvents with respect to water. The correlation coefficients for B3LYP and M06-2X calculations are shown in Table 2. A symmetrical distribution could be seen between the results of B3LYP and M06-2X, giving small differences between the two methods. The best correlations with experiments $\left(R^{2} \geq 0.7\right)$ are obtained for propan-2ol, propan-1-ol and methanol. The partition coefficient calculated for propan-1-ol with B3LYP provided the best correlation ( $\mathrm{R}^{2}$ of 0.73 ). From the observed tendency it seems that the behaviour of SDS micelles could resemble the behaviour with alcohol solvents with a moderate dielectric constant (of a range of about 20 to 33). It must be noted that the predicted partition among these solvents could not be directly obtained by traditional shake-flask assays as these solvents are miscible with water. However, these partitions could be obtained experimentally by appropriated thermodynamic cycles using a common immiscible solvent. In addition, from the values of Table 2, SDS behaviour is not well emulated by a solvent such as $N$-dodecane $\left(\mathrm{R}^{2}<0.1\right)$ although it has a chemical structure similar to the hydrophobic tail of SDS. Instead, it seems that the hydrophilic properties of the sulphate group of SDS and the hydrophobic properties of the dodecyl tail are captured by alcohols with moderate dielectric constant, such as propan-1-ol, propan-2-ol and methanol. 
Table 2. Linear regression parameters obtained for the correlation of the calculated LogP in 15 different solvents with respect to the experimental partition coefficients in SDS micelles. Solvents are sorted as a function of their dielectric constant.

\begin{tabular}{cccc}
\hline Solvent & $\begin{array}{c}\text { Dielectric } \\
\text { Constant }\end{array}$ & $\begin{array}{c}\mathbf{R}^{\mathbf{2}} \\
\text { B3LYP }\end{array}$ & $\begin{array}{c}\mathbf{R}^{\mathbf{2}} \\
\text { M06-2X }\end{array}$ \\
\hline Heptane & 1.92 & 0.04 & 0.07 \\
Cyclohexane & 2.02 & 0.03 & 0.06 \\
N-dodecane & 2.03 & 0.08 & 0.04 \\
Pyridine & 2.35 & 0.20 & 0.30 \\
Diethyl sulfide & 6.14 & 0.12 & 0.22 \\
Acetic acid & 6.2 & 0.03 & 0.09 \\
Decan-1-ol & 7.53 & 0.26 & 0.34 \\
Octanol & 10.3 & 0.40 & 0.48 \\
Propan-2-ol & 19.26 & 0.68 & 0.68 \\
Acetone & 20.16 & 0.19 & 0.35 \\
Propan-1-ol & 21.03 & 0.73 & 0.69 \\
Methanol & 32.61 & 0.71 & 0.62 \\
1,2-ethane diol & 40.24 & 0.12 & 0.26 \\
Dimethyl sulfoxide & 46 & 0.13 & 0.23 \\
Formic acid & 58 & 0.06 & 0.10 \\
\hline
\end{tabular}

The obtained linear regression for these alcohol-water partition coefficients is indicated in Table 3. Independently of the functional used in the DFT calculations (B3LYP and M06-2X), the obtained slopes are similar. This indicates a similar prediction for both sets of calculations.

Table 3. Best linear regressions obtained to predict the $\log \mathrm{P}$ in SDS micelles using DFT calculations. Results from B3LYP and M06-2X functionals with 6-31++G ** basis set using SMD for propan-1-ol, propan-2-ol and methanol are indicated. $x$ refers to predicted $\log \mathrm{P}$ alcohol/water, and $y$ refers to the predicted $\log \mathrm{P}$ in SDS micelles. Below each slope and intercept, a 95\% confidence interval is indicated in parentheses.

\begin{tabular}{ccccc}
\hline Solvent & B3LYP & \multicolumn{1}{c}{ M06-2X } \\
\hline Propan-1-ol & $\mathrm{y}=1.2 \mathrm{x}-0.2$ & $\mathrm{y}=1.2 \mathrm{x}-0.2$ \\
& $(1.0,1.4)(-0.7,0.3)$ & $(1.0,1.4)(-0.7,0.4)$ \\
Propan-2-ol & $\mathrm{y}=1.1 \times-0.0$ & $\mathrm{y}=1.3 \times-0.3$ \\
& $(0.9,1.4)(-0.5,0.6)$ & $(1.0,1.5)(-0.9,0.3)$ \\
Methanol & $\mathrm{y}=1.2 \times-0.2$ & $\mathrm{y}=1.3 \mathrm{x}-0.4$ \\
& $(1.0,1.4)(-0.7,0.3)$ & $(1.0,1.6) \quad(-1.1,0.3)$ \\
\hline
\end{tabular}

From the three solvent systems, the one that provides the best linear correlation with the experimental $\log \mathrm{P}_{\mathrm{SDS}}$ in SDS micelles was the $\log \mathrm{P}_{\text {propan-1-ol } / \text { water }}$ (Figure 1). Correlations for propan-2-ol and methanol are shown in Figures S2 and S3 in the Supplementary Materials. Among the two functionals, calculated $\log \mathrm{P}_{\text {propan-1-ol/water values with the }}$ B3LYP functional and 6-311++G ** give the best correlation, with an estimated $R^{2}$ of 0.73 . However, attending to the standard errors and confidence intervals, all the equations in Table 3 show intercept coefficients that are not significantly different from 0 . To sum up, these results indicate that a linear correlation between the partition coefficient of the studied set of molecules in SDS micelles with the $\log \mathrm{P}$ partition coefficient in propan-1-ol/water, propan-2-ol/water, and methanol/water is established. 


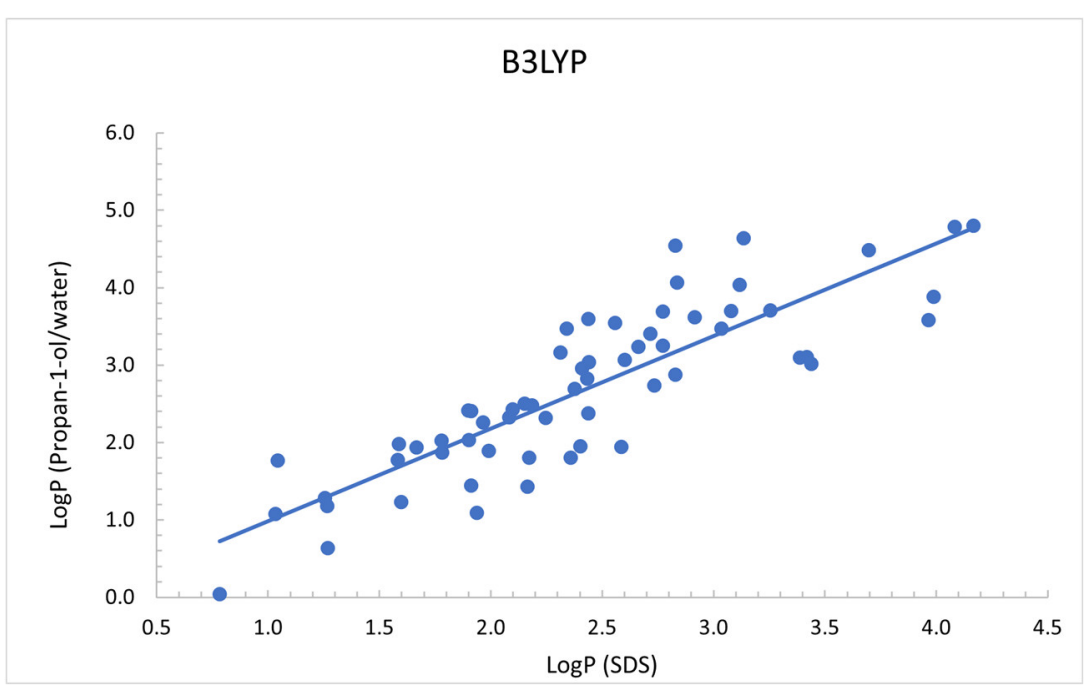

(a)

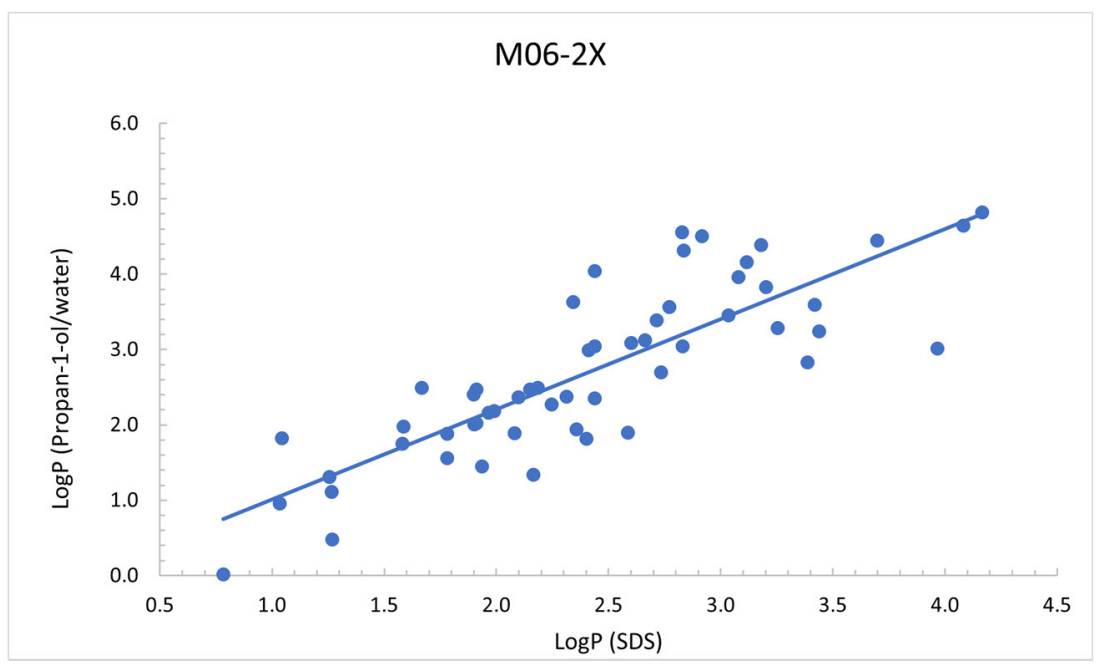

(b)

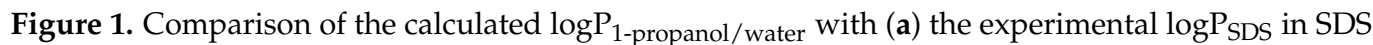
micelles for B3LYP and (b) M06-2X DFT calculations.

\subsection{Comparison with Experimental Octanol/Water Partition Coefficients}

To have an estimation of the accuracy of the calculated partition coefficients in different solvents, a comparison of predicted and experimental partition coefficients in octanol/water were performed (Table 4 and Figure 2).

Table 4. Linear Regression Parameters Obtained for the Calculated $\log \mathrm{P}_{\mathrm{O} / \mathrm{W}}$ (octanol/water) with Respect to the Experimental partition coefficients in octanol/water. Statistical Error Assessment of the Linear Regression Terms Based on Applied Computational Models are indicated. Below each slope, a $95 \%$ confidence interval is indicated in parentheses.

\begin{tabular}{cccccc}
\hline Density Functinal & Slope & $\mathbf{R}^{2}$ & MAE & RMSE & MSE \\
\hline B3LYP & $\begin{array}{c}0.67 \\
(0.52,0.82) \\
0.71\end{array}$ & 0.60 & 0.58 & 0.79 & 0.63 \\
M06-2X & $(0.57,0.86)$ & 0.65 & 0.64 & 0.79 & 0.63 \\
\hline
\end{tabular}




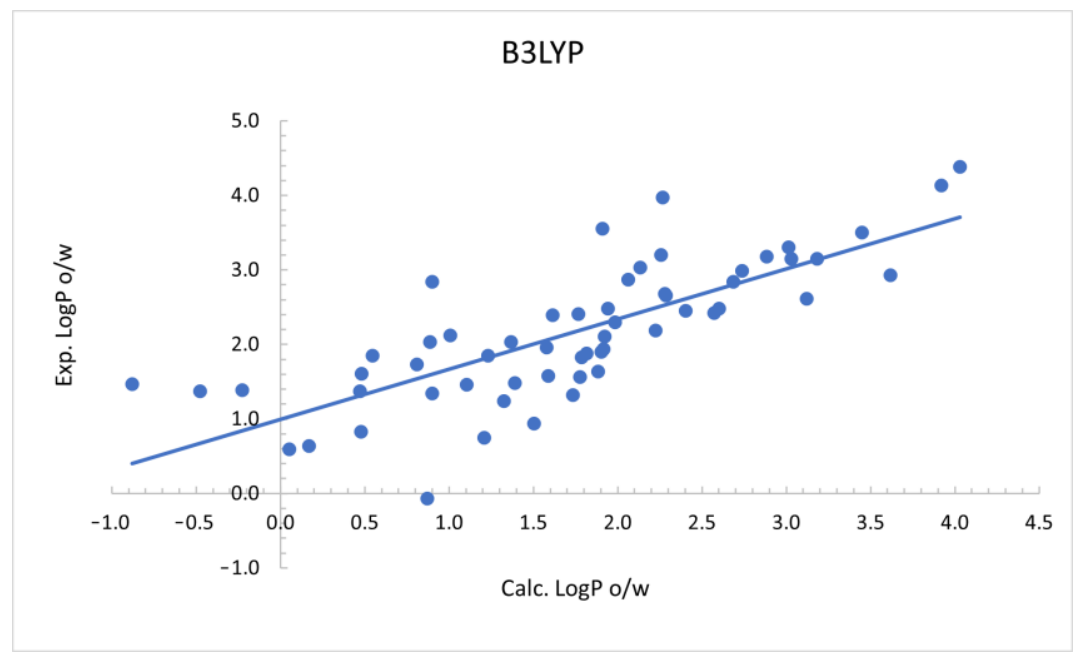

(a)

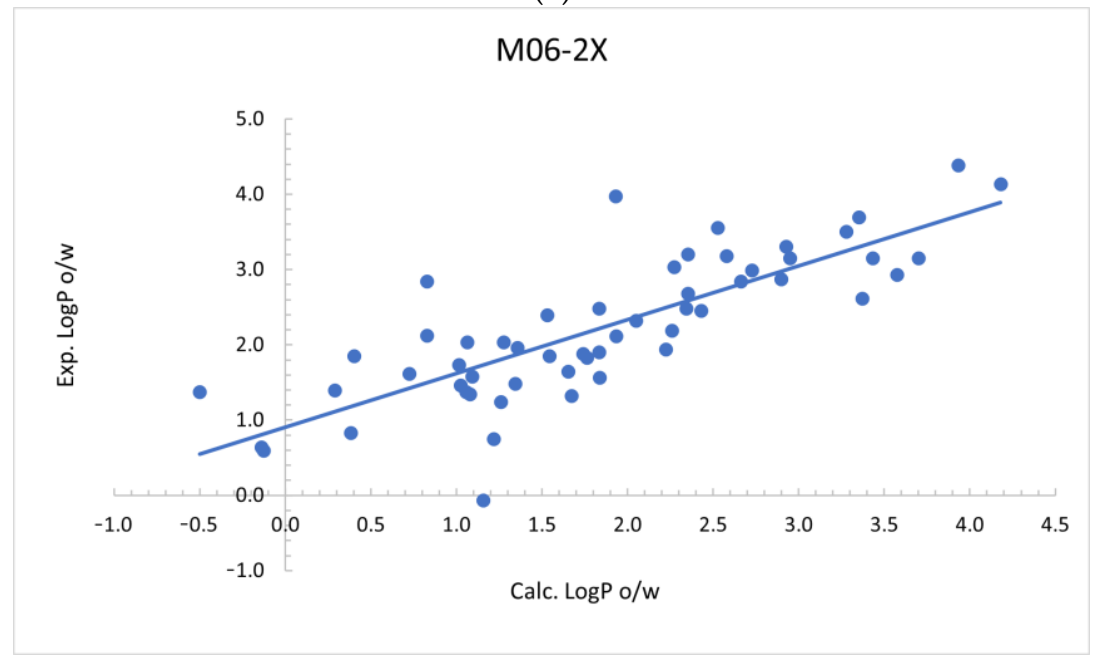

(b)

Figure 2. Comparison of the calculated $\log \mathrm{P}$ in octanol/water with the experimental $\log \mathrm{P}$ in (a) octanol/water for B3LYP and (b) M06-2X DFT calculations.

A significant linear correlation was obtained comparing the $\log \mathrm{P}_{\mathrm{o}} / \mathrm{w}$ with experimental values, both with the B3LYP and M06-2X functionals. Considering the confidence intervals obtained for both coefficients of the linear regression (Table S3 in the Supplementary Materials), the predictions obtained using both functionals are statistically equivalent. In general, symmetrical results are obtained for both methods. A better Pearson correlation coefficient is obtained with the M06-2X functional. However, the comparison of MAE, MSE and RMSE shows similar results for both functionals. In general, the good prediction rates for both methods allow us to make meaningful comparisons between calculated values with the SMD solvation model with two functional (B3LYP, M06-2X) with 6-311++G ** basis set. The MAE is about half a logarithmic unit between the calculated and experimental partition coefficients for octanol/water. Therefore, the DFT-based SMD solvation model appears to be adequate to predict the octanol/water partition coefficient for this set of molecules. A similar degree of prediction could be expected for partition coefficients among other solvents, although experimental validation will be necessary.

\section{Conclusions}

To develop a faster computational strategy to obtain $\log \mathrm{P}$ for micelle/water systems, we propose to correlate the $\log \mathrm{P}$ of available experimental values of a particular micelle with different $\log \mathrm{P}$ solvent/water systems, which have similar physicochemical/polarity 
characteristics to the micelle. In this study, a linear correlation between the partition coefficient of 63 molecules in SDS micelles with the logP partition coefficient in propan-1$\mathrm{ol} /$ water, propan-2-ol/water, and methanol/water have been found. Propan-1-ol partition coefficients were predicted within the framework of DFT using two functionals (B3LYP and M06-2X) with the 6-311++G ** basis set obtaining the best correlation between calculated $\log P$ and experimental $\log P$ SDS values. This methodology allows us to estimate with only two relatively fast DFT calculations of the partition coefficient of any molecule to a solution of SDS micelles: one DFT calculation in water and the other in propan-1-ol. Moreover, this procedure could also be used to determine partition coefficients in other type of micelles, determining first the appropriated solvent that captures the main physicochemical properties of the micelles. In addition, the partition coefficient of octanol/water was also estimated within the framework of DFT calculations with B3LYP and M062-X functionals, obtaining a good agreement between the calculated and experimental data.

Supplementary Materials: The following are available online at https://www.mdpi.com/article/ 10.3390/sym13091750/s1, Figure S1: Chemical structures of the solvents used in DFT calculations; Figure S2: Comparison of the calculated $\log \mathrm{P}$ in propan-2-ol/water with the experimental $\log \mathrm{P}$ in SDS micelle system; Figure S3: Comparison of the calculated $\log \mathrm{P}$ in methanol/water with the experimental $\log \mathrm{P}$ in SDS micelle system. Table S1: Predicted partition coefficients for octanol/water, propan-1-ol/water, propan-2-ol/water and methanol/water with B3LYP calculations. Table S2: Predicted partition coefficients for octanol/water, propan-1-ol/water, propan-2-ol/water and methanol/water with M06-2X calculations. Table S3: Statistical parameters obtained from the linear regressions for B3LYP and M06-2X calculations. Table S4: List of experimental LogPo/w values. Spreadsheet with thermochemical data for propan-1-ol, propan-2-ol and methanol. Equations of the statistical measures used in the analysis.

Author Contributions: Conceptualization, S.M.; computational methodology, S.M., L.S. and M.N.; experimental methodology, E.F.; software, L.S.; formal analysis, S.M., L.S., M.N., F.M. and V.S.; resources, F.M. and S.M.; data curation, L.S.; writing —original draft preparation, L.S.; writingreview and editing, S.M., M.N., E.F., F.M. and V.S.; supervision, S.M. All authors have read and agreed to the published version of the manuscript.

Funding: S.M. and F.M. acknowledge the financial support from Generalitat de Catalunya (Grant 2017SGR1033). S.M. and F.M. acknowledge Spanish Structures of Excellence María de Maeztu program through (Grant MDM-2017\{0767).

Data Availability Statement: Data obtained and derived from calculations and inputs and outputs of Gaussian calculations will be available on request to the authors.

Conflicts of Interest: The authors declare no conflict of interest. The funders had no role in the design of the study; in the collection, analyses, or interpretation of data; in the writing of the manuscript, or in the decision to publish the results.

\section{References}

1. Bannan, C.C.; Calabró, G.; Kyu, D.Y.; Mobley, D.L. Calculating Partition Coefficients of Small Molecules in Octanol/Water and Cyclohexane/Water. J. Chem. Theory Comput. 2016, 12, 4015-4024. [CrossRef]

2. Amézqueta, S.; Subirats, X.; Fuguet, E.; Roses, M.; Rafols, C. Octanol-water partition constant. Liquid-Phase Extraction. In Handbooks in Separation Science; Poole, C.F., Ed.; Elsevier: Amsterdam, The Netherlands, 2019; pp. 183-208. [CrossRef]

3. Koehler, M.G.; Grigoras, S.; Dunn, W.J. The Relationship Between Chemical Structure and the Logarithm of the Partition Coefficient. Quant. Struct. Relatsh. 1988, 7, 150-159. [CrossRef]

4. Schwarze, M.; Volovych, I.; Wille, S.; Mokrushina, L.; Arlt, W.; Schomacker, R. Partition Coefficients of Itaconates in AqueousMicellar Solutions: Measurements and Predictions with COSMO-RS. Ind. Eng. Chem. Res. 2012, 51, 1846-1852. [CrossRef]

5. Fuguet, E.; Ràfols, C.; Bosch, E.; Abraham, M.H.; Rosés, M. Solute-solvent interactions in micellar electrokinetic chromatography III. Characterization of the selectivity of micellar electrokinetic chromatography Systems. J. Chromatogr. A 2002, 942, 237-248. [CrossRef]

6. Fuguet, E.; Ràfols, C.; Bosch, E.; Abraham, M.H.; Rosés, M. Erratum to “Solute-solvent interactions in micellar electrokinetic chromatography. III. Characterization of the selectivity of micellar electrokinetic chromatography Systems". J. Chromatogr. A 2009, 1216, 6877-6879. [CrossRef] 
7. Fuguet, E.; Ràfols, C.; Bosch, E.; Rosés, M. Characterization of the solvation properties of sodium n-dodecyl sulphate micelles in buffered and unbuffered aqueous phases by solvatochromic indicators. Langmuir 2003, 19, 55-62. [CrossRef]

8. Ingram, T.; Storm, S.; Kloss, L.; Mehling, T.; Jakobtorweihen, S.; Smirnova, I. Prediction of micelle/water and liposome/water partition coefficients based on molecular dynamics simulations, COSMO-RS, and COSMOmic. Langmuir 2013, $29,3527-3537$. [CrossRef] [PubMed]

9. Ritter, E.; Yordanova, D.; Gerlach, T.; Smirnova, I.; Jakobtorweihen, S. Molecular dynamics simulations of various micelles to predict micelle water partition equilibria with COSMOmic: Influence of micelle size and structure. Fluid Phase Equilibria 2016, 422, 43-55. [CrossRef]

10. Yordanova, D.; Ritter, E.; Gerlach, T.; Jensen, J.H.; Smirnova, I.; Jakobtorweihen, S. Solute Partitioning in Micelles: Combining Molecular Dynamics Simulations, COSMOmic, and Experiments. J. Phys. Chem. B 2017, 121, 5794-5809. [CrossRef]

11. Turchi, M.; Kognole, A.A.; Kumar, A.; Cai, Q.; Lian, G.; Mackerell, A.D. Predicting Partition Coefficients of Neutral and Charged Solutes in the Mixed SLES-Fatty Acid Micellar System. J. Phys. Chem. B 2020, 124, 1653-1664. [CrossRef]

12. Nedyalkova, M.; Madurga, S.; Tobiszewski, M.; Simeonov, V. Calculating the Partition Coefficients of Organic Solvents in Octanol/Water and Octanol/Air. J. Chem. Inf. Model. 2019, 59, 2257-2263. [CrossRef] [PubMed]

13. Jones, M.R.; Brooks, B.R.; Wilson, A.K. Partition coefficients for the SAMPL5 challenge using transfer free energies. J. Comput.Aided Mol. Des. 2016, 30, 1129-1138. [CrossRef]

14. Chou, J.T.; Jurs, P.C. Computer-Assisted Computation of Partition Coefficients from Molecular Structures Using Fragment Constants. J. Chem. Inf. Comput. Sci. 1979, 19, 172-178. [CrossRef]

15. Ghose, A.K.; Crippen, G.M. Atomic Physicochemical Parameters for Three-Dimensional Structure-Directed Quantitative StructureActivity Relationships I. Partition Coefficients as a Measure of Hydrophobicity. J. Comput. Chem. 1986, 7, 565-577. [CrossRef]

16. Tielker, N.; Tomazic, D.; Eberlein, L.; Kast, S.M.; Güssregen, S. The SAMPL6 challenge on predicting octanol-water partition coefficients from EC-RISM theory. J. Comput.-Aided Mol. Des. 2020, 34, 453-461. [CrossRef]

17. Lyubartsev, A.P.; Jacobsson, S.P.; Sundholm, G.; Laaksonen, A. Solubility of organic compounds in water/octanol systems. A expanded ensemble molecular dynamics simulation study of log P parameters. J. Phys. Chem. B 2001, 105, 7775-7782. [CrossRef]

18. Hodges, G.; Eadsforth, C.; Bossuyt, B.; Bouvy, A.; Enrici, M.H.; Geurts, M.; Kotthoff, M.; Michie, E.; Miller, D.; Müller, J.; et al. A comparison of $\log \mathrm{K}$ ow (n-octanol-water partition coefficient) values for non-ionic, anionic, cationic and amphoteric surfactants determined using predictions and experimental methods. Environ. Sci. Eur. 2019, 31, 1-18. [CrossRef]

19. Klamt, A.; Eckert, F.; Reinisch, J.; Wichmann, K. Prediction of cyclohexane-water distribution coefficients with COSMO-RS on the SAMPL5 data set. J. Comput.-Aided Mol. Des. 2016, 30, 959-967. [CrossRef]

20. Bannan, C.C.; Burley, K.H.; Chiu, M.; Shirts, M.R.; Gilson, M.K.; Mobley, D.L. Blind prediction of cyclohexane-water distribution coefficients from the SAMPL5 challenge. J. Comput.-Aided Mol. Des. 2016, 30, 927-944. [CrossRef] [PubMed]

21. Rustenburg, A.S.; Dancer, J.; Lin, B.; Feng, J.A.; Ortwine, D.F.; Mobley, D.L.; Chodera, J.D. Measuring experimental cyclohexanewater distribution coefficients for the SAMPL5 challenge. J. Comput.-Aided Mol. Des. 2016, 30, 945-958. [CrossRef]

22. Marenich, A.V.; Cramer, C.J.; Truhlar, D.G. Perspective on Foundations of Solvation Modeling: The Electrostatic Contribution to the Free Energy of Solvation. J. Chem. Theory Comput. 2008, 4, 877-887. [CrossRef] [PubMed]

23. Marenich, A.V.; Cramer, C.J.; Truhlar, D.G. Universal Solvation Model Based on Solute Electron Density and on a Continuum Model of the Solvent Defined by the Bulk Dielectric Constant and Atomic Surface Tensions. J. Phys. Chem. B 2009, 113, 6378-6396. [CrossRef]

24. Becke, A.D. Density-functional exchange-energy approximation with correct asymptotic behavior. Phys. Rev. A 1988, 38, 3098-3100. [CrossRef] [PubMed]

25. Becke, A.D. Density-Functional thermochemistry. III. The role of exact exchange. J. Chem. Phys. 1993, 98, 5648-5652. [CrossRef]

26. Stephens, P.J.; Devlin, F.J.; Chabalowski, C.F.; Frisch, M.J. Ab Initio Calculation of Vibrational Absorption and Circular Dichroism Spectra Using Density Functional Force Fields. J. Phys. Chem. 1994, 98, 11623-11627. [CrossRef]

27. Zhao, Y.; Truhlar, D. The M06 suite of density functionals for main group thermochemistry, thermochemical kinetics, noncovalent interactions, excited states, and transition elements: Two new functionals and systematic testing of four M06-class functionals and 12 other functionals. Theor. Chem. Acc. 2008, 120, 215-241. [CrossRef]

28. Fuguet, E.; Ràfols, C.; Rosés, M.; Bosch, E. Critical micelle concentration of surfactants in aqueous buffered and unbuffered systems. J. Anal. Chim. Acta 2005, 548, 95-100. [CrossRef]

29. Mennucci, B.; Cancès, E.; Tomasi, J. Evaluation of Solvent Effects in Isotropic and Anisotropic Dielectrics and in Ionic Solutions with a Unified Integral Equation Method: Theoretical Bases, Computational Implementation, and Numerical Applications. J. Phys. Chem. B 1997, 101, 10506-10517. [CrossRef]

30. Frisch, M.J.; Trucks, G.W.; Schlegel, H.B.; Scuseria, G.E.; Robb, M.A.; Cheeseman, J.R.; Scalmani, G.; Barone, V.; Petersson, G.A.; Nakatsuji, H.; et al. Gaussian 16, Revision, C.01; Gaussian, Inc.: Wallingford, CT, USA, 2016.

31. Hanwell, M.D.; Curtis, D.E.; Lonie, D.C.; Vandermeersch, T.; Zurek, E.; Hutchison, G.R. Avogadro: An advanced semantic chemical editor, visualization, and analysis platform. J. Cheminform. 2012, 4, 17. [CrossRef] 